\title{
Increasing Alkyl Chain Length in a Series of Layered Metal-Organic Frameworks Aids Ultrasonic Exfoliation to Form Nanosheets
}

\author{
David J. Ashworth, ${ }^{\dagger}$ Thomas M. Roseveare, ${ }^{\dagger}$ Andreas Schneemann, ${ }^{\ddagger} \S^{\circ}$ Max Flint, \\ Irene Dominguez Bernáldes, ${ }^{\dagger}$ Pia Vervoorts, ${ }^{\ddagger}, \S$ Roland A. Fischer, ${ }^{\ddagger},\left(\odot\right.$ Lee Brammer, ${ }^{\dagger}$ \\ and Jonathan A. Foster* ${ }^{\dagger}$ (i) \\ ${ }^{\dagger}$ Department of Chemistry, University of Sheffield, Brook Hill, Sheffield S3 7HF, U.K. \\ ${ }^{*}$ Department of Chemistry, Technische Universität München, Lichtenbergstraße 4, 85748 Garching, Germany \\ ${ }^{\S}$ Catalysis Research Centre, Technische Universität München, Ernst-Otto-Fischer Straße 1, 85748 Garching, Germany
}

Supporting Information

\begin{abstract}
Metal-organic framework nanosheets (MONs) are attracting increasing attention as a diverse class of two-dimensional materials derived from metal-organic frameworks (MOFs). The principles behind the design of layered MOFs that can readily be exfoliated to form nanosheets, however, remain poorly understood. Here we systematically investigate an isoreticular series of layered MOFs functionalized with alkoxy substituents in order to understand the effect of substituent alkyl chain length on the structure and properties of the resulting nanosheets. A series of 2,5-alkoxybenzene1,4-dicarboxylate ligands $\left(\mathrm{O}_{2} \mathrm{CC}_{6} \mathrm{H}_{2}(\mathrm{OR})_{2} \mathrm{CO}_{2}, \mathrm{R}=\right.$ methyl-pentyl, $1-5$, respectively) was used to synthesize copper paddle-wheel MOFs. Rietveld and Pawley fitting of powder diffraction patterns for compounds $\mathrm{Cu}(3-5)(\mathrm{DMF})$ showed they adopt an isoreticular series
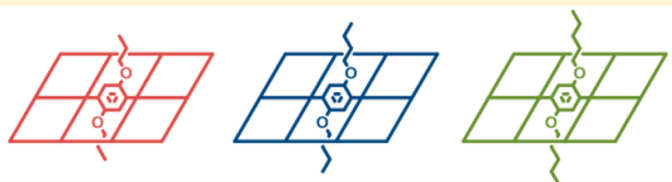

Increasing alkyl chain length, decreasing nanosheet height
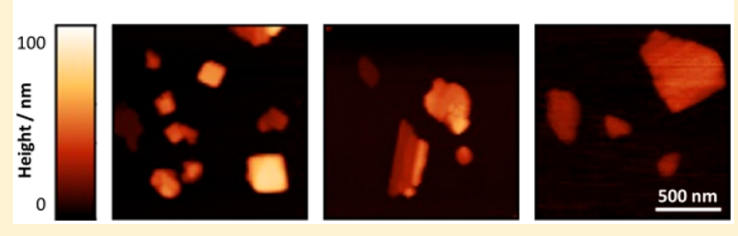
with two-dimensional connectivity in which the interlayer distance increases from $8.68 \AA\left(\mathrm{R}=\right.$ propyl) to $10.03 \AA$ ( $\mathrm{R}=$ pentyl). Adsorption of $\mathrm{CO}_{2}$ by the MOFs was found to increase from 27.2 to $40.2 \mathrm{~cm}^{3} \mathrm{~g}^{-1}$ with increasing chain length, which we attribute to the increasing accessible volume associated with increasing unit-cell volume. Ultrasound was used to exfoliate the layered MOFs to form MONs, with shorter alkyl chains resulting in higher concentrations of exfoliated material in suspension. The average height of MONs was investigated by AFM and found to decrease from $35 \pm 26$ to $20 \pm 12 \mathrm{~nm}$ with increasing chain length, with the thinnest MONs observed being only $5 \mathrm{~nm}$, corresponding to five framework layers. These results indicate that careful choice of ligand functionalities can be used to tune nanosheet structure and properties, enabling optimization for a variety of applications.
\end{abstract}

\section{INTRODUCTION}

Metal-organic framework nanosheets (MONs) are freestanding, nominally two-dimensional materials formed by the coordination of organic ligands to metal ions or clusters. ${ }^{1-4}$ MONs share many of the advantages of other metal-organic materials, such as the ease with which their structures can be varied and new properties introduced. However, they also benefit from the high aspect ratio, vast external surface area, and nanoscopic dimensions of other two-dimensional materials such as graphene, boron nitride, and molybdenum disulfide. These properties have already enabled MONs to outperform their bulk counterparts in a variety of applications, including gas separation, ${ }^{5}$ water purification, ${ }^{6}$ sensing, ${ }^{7-12}$ catalysis, ${ }^{13-20}$ and optoelectronics. ${ }^{21-26}$

The development of metal-organic frameworks (MOFs) over the past two decades has been focused on understanding how to design and tune the properties of open porous threedimensional structures, for applications including gas storage, ${ }^{27}$ catalysis, ${ }^{28}$ and sensing. ${ }^{29-31}$ During this time, a large number of layered MOFs have been reported. It is these MOFs that provide a platform for the development of MONs. Two distinct approaches have emerged to convert layered MOFs into MONs: (1) "bottom-up" self-assembly of subcomponents in the presence of a directing interface ${ }^{5,32}$ or chemical species $^{33,34}$ and (2) "top-down" exfoliation from layered MOFs. For the latter approach, a wide variety of methods have been developed including freeze-thaw, ${ }^{35}$ ball-milling, ${ }^{36,37}$ intercalation, ${ }^{38,39}$ and ultrasonication. ${ }^{7,36,40-49}$ Among these, liquid exfoliation using ultrasound is one of the most widely applicable and readily scalable methods, which has been widely applied in the exfoliation of other two-dimensional (2D) materials. ${ }^{50-53}$ The vast majority of MONs reported to date are based on known MOF structures being repurposed to form nanosheets. Understanding how to optimize the design of layered MOFs to facilitate exfoliation into free-standing

Received: April 17, 2019

Published: August 6, 2019 
nanosheets is therefore an important and necessary new crystal engineering challenge.

Functionalization of 2,5-dihydroxybenzene-1,4-dicarboxylic acid $\left(\mathrm{H}_{2} \mathrm{DHBDC}\right)$ with pendant flexible substituents has proved useful for understanding the structure-property relationships of three-dimensional MOFs, particularly regarding their gas adsorption properties, as well as their framework flexibility, introducing new behaviors and optimizing their design for the adsorption of specific gases. ${ }^{54,55}$ In most of these systems, the pendant chains sit within the pores of the MOF and do not affect the overall structure, although they can influence the architecture that is formed. ${ }^{54}$ We have recently developed this approach further in a series of layered MOFs designed to incorporate short alkyl-ether chains between the layers intended to aid exfoliation by weakening interlayer interactions and increasing interactions with solvent molecules. ${ }^{47}$ In a related study, two layered MOFs functionalized with either $-\mathrm{O}\left(\mathrm{CH}_{2}\right)_{4} \mathrm{CH}_{3}$ or $-\mathrm{O}\left(\mathrm{CH}_{2}\right)_{3} \mathrm{OCH}_{3}$ chains which bestowed hydrophobic or hydrophilic character, respectively, were exfoliated in a wide range of solvents. ${ }^{56}$ The more hydrophobic system formed thinner, more well-defined nanosheets comprising fewer framework layers. Optimization and control of the exfoliation process by framework design, however, remain key challenges, which we seek to address in the current study.

Here, we report a series of layered MOFs (Figure 1) formed using DHBDC $^{2-}$ ligands functionalized with alkyl chains

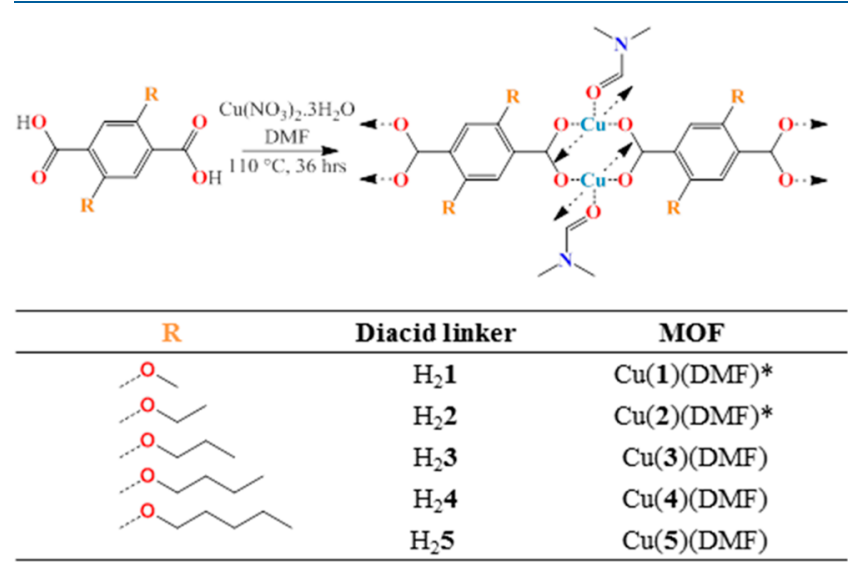

Figure 1. General reaction scheme for the targeted syntheses of MOFs $[\mathrm{Cu}(\boldsymbol{n})(\mathrm{DMF})]_{n}$, where $\boldsymbol{n}=\mathbf{1}-\mathbf{5}$. R groups in dicarboxylic acid ligands precursors $\mathrm{H}_{2} 1$ to $\mathrm{H}_{2} 5$ are defined, and the terminology used throughout this Article is provided. [*When using $\mathrm{H}_{2} \mathbf{1}$ and $\mathrm{H}_{2} 2$, the anticipated MOF structures were not formed (see text)].

(methyl to pentyl). We show that increasing chain length improves exfoliation to yield MONs of improved aspect ratio. We suggest that increasing chain length weakens the interlayer interactions and improves interactions of the framework layers with solvent molecules, leading to the enhanced exfoliation. The study is underpinned by a detailed characterization of the MOF series in their solvated and unsolvated forms, enabling the effect of alkyl chain length on their structure to be understood. We also report on the $\mathrm{CO}_{2} / \mathrm{N}_{2}$ adsorption behavior of the MOFs, which can be related to the trend in their unit-cell dimensions.

\section{RESULTS AND DISCUSSION}

2.1. MOF Syntheses and Characterization. Dicarboxylic acids $\mathrm{H}_{2} 1-\mathrm{H}_{2} 4^{54}$ and $\mathrm{H}_{2} 5^{56}$ were synthesized via Williamson etherification of dimethoxy-2,5-dihydroxybenzenedicarboxylate with iodomethane or 1-bromoalkane (where alkane = ethanepentane) following previously reported protocols. High yields (83-91\%) of 2,5-bis(alkoxy)-1,4-benzenedicarboxylic acid (alkoxy = methoxy-pentoxy) were obtained, and compound purity was confirmed through ${ }^{1} \mathrm{H}$ NMR spectroscopy (Figures S1-S5). MOFs were formed by the solvothermal reaction of $\mathrm{H}_{2} \mathbf{1}-\mathrm{H}_{2} 5$ (10 mol \% excess) and copper nitrate in DMF at $110{ }^{\circ} \mathrm{C}$ for $36 \mathrm{~h}$. Green microcrystalline powders were obtained following slow cooling of the mixtures to room temperature and were then analyzed by powder X-ray diffraction (PXRD), Fourier-transform infrared (FTIR) spectroscopy, thermogravimetric analysis (TGA), and elemental analysis to understand their structure.

In line with our previous study, $\mathrm{H}_{2} 5$ was found to give a compound with the formula $\mathrm{Cu}(5)(\mathrm{DMF})$. TGA shows a $15.2 \%$ mass loss in the region $110-230{ }^{\circ} \mathrm{C}$ (theoretical $15.5 \%$ mass loss, Figure S7); FTIR shows the $\mathrm{C}=\mathrm{O}$ stretch of coordinated DMF at $1668 \mathrm{~cm}^{-1}$ (Figure S6), shifted from the expected wavenumber of $1676 \mathrm{~cm}^{-1}$ for free $\mathrm{DMF}, 57$ and elemental analysis shows good agreement for the empirical formula $\mathrm{CuC}_{21} \mathrm{H}_{31} \mathrm{NO}_{7}$ (Table S1).

For the first time, we were also able to determine the structure of $\mathrm{Cu}(5)$ (DMF) (Figure 2b) from a high-resolution PXRD pattern collected at Diamond Light Source, beamline I11, and refine the structural model by Rietveld methods (see Figures S15 and S16; CCDC 1910582). Carboxylate groups of four ligands of $\mathbf{5}$ coordinate to $\mathrm{Cu}_{2}$ dimers in a bidentate bridging manner, forming the paddle-wheel (PW) secondary building unit (SBU) (Figure 1). DMF is coordinated at the axial positions to form a distorted square-pyramidal coordination environment around the $\mathrm{Cu}_{2}$ atoms, which are separated by a distance of $3.16 \AA$. Ligand 5 connects adjacent PWs, which form a square-net topology within a layer (Figure 2c). The pentoxy chains and DMF molecules extend out of the layer interdigitating with those in adjacent layers, holding them together through van der Waals forces (Figure 2b). This layered structure is isoreticular with that of MOF- $2^{58}$ and our previously reported single-crystal structure for $\mathrm{Zn}(\mathbf{X})(\mathrm{DMF})$ where $\mathbf{X}$ is 2,5-bis(3-methoxypropoxy)-1,4-benzenedicarboxylate (i.e., $\left.\mathrm{R}=\mathrm{O}\left(\mathrm{CH}_{2}\right)_{3} \mathrm{OCH}_{3}\right)$. ${ }^{47}$

Dicarboxylic acids $\mathrm{H}_{2} n(n=3,4)$ form MOFs $\mathrm{Cu}(\boldsymbol{n})$ (DMF), with structures closely related to $\mathrm{Cu}(5)(\mathrm{DMF})$. Mass losses corresponding to the loss of coordinated DMF were observed by TGA over the temperature range of $90-240{ }^{\circ} \mathrm{C}$; FTIR showed the $\mathrm{C}=\mathrm{O}$ stretch around $1665 \mathrm{~cm}^{-1}$ of coordinated DMF; elemental analysis was consistent with the anticipated formula unit (Table S1). Pawley refinements of synchrotron PXRD data indicated unit cell parameters similar to $\mathrm{Cu}(\mathbf{5})(\mathrm{DMF})$ (Table 1 and Figures S11-S13), which suggests that they adopt the same square-grid topology. There is an increase in the volume of the unit cell with increasing alkyl chain length (3-5) from 1009 to $1155 \AA^{3}$. However, it is difficult to attribute this to expansion along a single axis because of the triclinic lattice symmetry. The flexibility of the alkyl chains, potential of the aromatic rings to rotate, and interplay with coordinated solvent molecules and pores mean that the effect of each additional methylene unit is likely to be more subtle than simply moving the layers apart. 


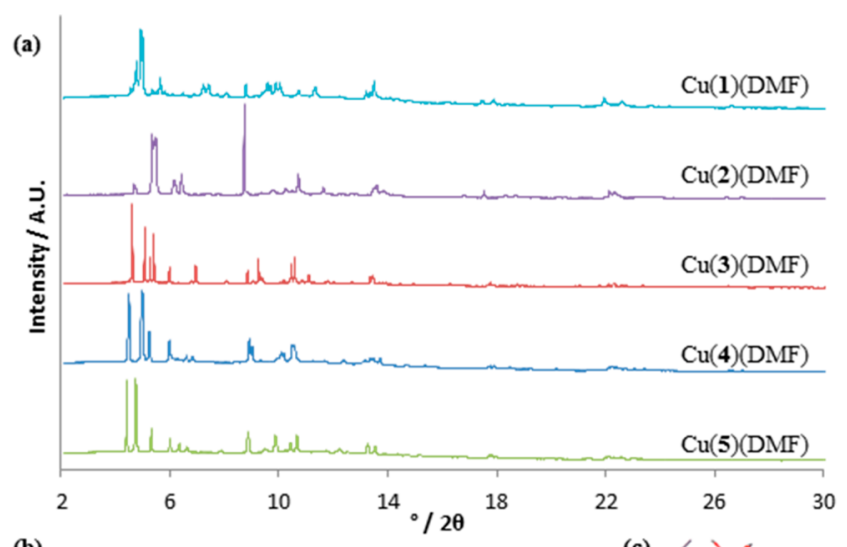

(b)

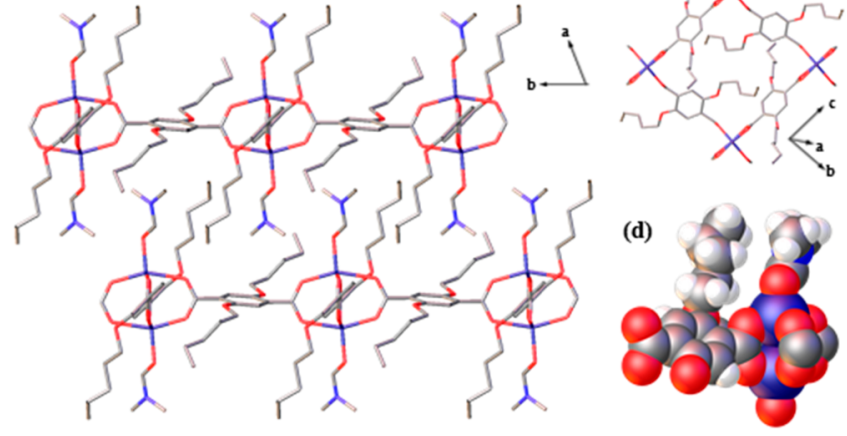

Figure 2. (a) PXRD patterns of microcrystalline powders resulting from the syntheses of $\mathrm{Cu}(\mathbf{1}-\mathbf{5})(\mathrm{DMF})$, collected at Diamond Light Source, beamline I11 $(\lambda=0.826015 \AA)$. (b) Crystal structure of $\mathrm{Cu}(5)(\mathrm{DMF})$ as refined through Rietveld methods, viewed down the $c$-axis. $\mathrm{H}$ atoms are omitted for clarity. (c) Square net structure of $\mathrm{Cu}(5)$ (DMF), viewed down the $\mathrm{Cu}-\mathrm{PW} \mathrm{Cu}-\mathrm{Cu}$ axis. $\mathrm{H}$ atoms and coordinated DMF molecules omitted for clarity. (d) Space-filling view of $\mathrm{Cu}(5)(\mathrm{DMF})$ showing $-\mathrm{O}\left(\mathrm{CH}_{2}\right)_{4} \mathrm{CH}_{3}$ chain and axial DMF packing. Copper, carbon, hydrogen, nitrogen, and oxygen atoms are depicted in purple, gray, white, blue, and red, respectively.

Rietveld refinements were attempted on high-resolution synchrotron PXRD patterns of $\mathrm{Cu}(n)$ (DMF) $(n=3,4)$ but it was not possible to solve the structures or to obtain models suitable for Rietveld refinement. However, $\mathrm{Cu}$ sites could be located from electron density maps. $\mathrm{Cu}_{2}$ units are situated with their centroids at the inversion centers within the structures (Table S5). Locating the $\mathrm{Cu}$ atoms allowed calculation of the
2D directional connectivity within layers (based on distances between $\mathrm{Cu}-\mathrm{Cu}$ centroids and length of a coordinating BDC ligand) and confirmed the anticipated square-grid network structure. This enabled calculation of the interlayer distance, which was found to increase $8.37<9.42<9.91 \AA$ from $\mathrm{Cu}(3)(\mathrm{DMF})$ to $\mathrm{Cu}(5)(\mathrm{DMF})$, correlating with increasing alkyl chain length (Figure S14). Particle morphologies of $\mathrm{Cu}(3-5)(\mathrm{DMF})$ were visualized using scanning electron microscopy (SEM). Platelets were observed with lateral dimensions in the range of $1-10 \mu \mathrm{m}$ (Figure S22).

Microcrystalline powders resulting from the reactions using $\mathrm{H}_{2} \boldsymbol{n}(\boldsymbol{n}=\mathbf{1}, 2)$ were similarly assessed. Elemental analyses (Table S1) were not consistent with the anticipated $\mathrm{Cu}(\boldsymbol{n})$ (DMF) $(n=1,2)$ formula. Indexing and Pawley refinement indicated a mixture of phases present. Guo et al. reported a structurally similar $\mathrm{Cu}-\mathrm{PW}$ MOF using 1, which has water capping the axial positions of the PW. Although TGA indicated that water may be present (4.5\% mass loss between 50 and 110 ${ }^{\circ} \mathrm{C}$ ), this phase was not observed in our synthesis (Figure S9). ${ }^{59}$ There are no examples of layered MOFs using 2 as the linker, to the best of our knowledge. Attempts to grow larger crystals of these materials were unsuccessful. Analogous syntheses using zinc and $\mathrm{H}_{2} 1$ or $\mathrm{H}_{2} 2$, attempting to grow single crystals, resulted in cubic crystals of MOFs isoreticular with the $3 \mathrm{D}$ MOF-5, ${ }^{60}$ in which 1,4-benzenedicarboxylate ligands (BDC) were replaced by $\mathbf{1}$ or $\mathbf{2}$, respectively. These materials were therefore excluded from further studies. Similar crystallizations using zinc and $\mathrm{H}_{2} 3-5$ also resulted in the $3 \mathrm{D}$ MOF-5 structure.

2.2. MOF Desolvation. We have previously observed that desolvation of this class of layered PW-MOFs can take place during ultrasonic exfoliation in noncoordinating solvents, for instance with acetonitrile $(\mathrm{MeCN})$ for $\mathrm{Cu}(5)(\mathrm{DMF}) .^{56}$ Desolvation is also anticipated to occur during gas adsorption measurements where frameworks are typically first activated through heating under dynamic vacuum (in our work, $160{ }^{\circ} \mathrm{C}$ for $10 \mathrm{~h}$ ), in order to remove any solvent coordinated or present from the pores. Before moving on to discuss the results of exfoliation or gas sorption studies, we therefore first sought to characterize the structures of the desolvated MOFs. This is particularly important for these systems as the parent, nonfunctionalized $\mathrm{Cu}(\mathrm{BDC})(\mathrm{DMF})$ undergoes a structural rearrangement upon desolvation, in which the carboxylate groups coordinate to the vacated axial position of the $\mathrm{Cu}_{2}$

Table 1. Unit Cell Parameters Determined through Pawley Refinements of PXRD Data (298 K) for Cu(3-5)(DMF) and $\mathrm{Cu}(3-5)$ and Rietveld Refinement of $\mathrm{Cu}(5)(\mathrm{DMF})^{a}$

\begin{tabular}{|c|c|c|c|c|c|c|c|c|c|c|c|}
\hline MOF & refinement & space group & $a(\AA)$ & $b(\AA)$ & $c(\AA)$ & $\alpha(\operatorname{deg})$ & $\beta$ (deg) & $\gamma(\operatorname{deg})$ & $\operatorname{vol}\left(\AA^{3}\right)$ & $R_{\mathrm{wp}}^{b}$ & $R_{\mathrm{wp}^{\prime}}{ }^{c}$ \\
\hline $\mathrm{Cu}(\mathrm{X})(\mathrm{DMF})^{47}$ & $\mathrm{~N} / \mathrm{A}$ & $P-1$ & 10.42 & 10.82 & 10.88 & 85.21 & 74.99 & 67.51 & 1095 & $\mathrm{~N} / \mathrm{A}$ & N/A \\
\hline $\mathrm{Cu}(3)(\mathrm{DMF})$ & Pawley & $P-1$ & 10.60 & 10.62 & 10.81 & 71.12 & 79.91 & 61.22 & 1009 & 0.0224 & 0.0894 \\
\hline $\mathrm{Cu}(4)(\mathrm{DMF})$ & Pawley & $P-1$ & 10.62 & 10.80 & 10.94 & 76.01 & 62.54 & 81.99 & 1080 & 0.0377 & 0.1539 \\
\hline $\mathrm{Cu}(5)(\mathrm{DMF})$ & Pawley & $P-1$ & 10.84 & 10.81 & 10.86 & 83.79 & 79.74 & 67.34 & 1155 & 0.0256 & 0.1129 \\
\hline $\mathrm{Cu}(5)(\mathrm{DMF})$ & Rietveld & $P-1$ & 10.84 & 10.80 & 10.85 & 83.82 & 79.82 & 67.44 & 1154 & 0.0517 & 0.2455 \\
\hline $\mathrm{Cu}(3)$ & Pawley & $P-1$ & 10.81 & 10.69 & 11.00 & 71.51 & 77.35 & 63.35 & 1072 & 0.0655 & 0.1278 \\
\hline $\mathrm{Cu}(4)$ & Pawley & $P-1$ & 10.42 & 10.72 & 11.03 & 77.27 & 64.11 & 82.87 & 1081 & 0.0474 & 0.0942 \\
\hline $\mathrm{Cu}(5)$ & Pawley & $P-1$ & 10.86 & 11.04 & 10.87 & 84.04 & 76.89 & 70.65 & 1197 & 0.0593 & 0.1101 \\
\hline
\end{tabular}

${ }^{a}$ All unit cell parameters are rounded to two decimal places; more accurate values and associated errors are provided in the Supporting Information (Table S3). $\mathbf{X}=2,5$-bis(3-methoxypropoxy)-1,4-benzenedicarboxylate (i.e., $\left.\mathrm{R}=\mathrm{O}\left(\mathrm{CH}_{2}\right)_{3} \mathrm{OCH}_{3}\right) .{ }^{b} R_{\mathrm{wp}}=\sqrt{\sum\left[w\left(Y_{\mathrm{obs}}-Y_{\text {calc }}\right)^{2}\right] / \sum\left[w Y_{\text {obs }}{ }^{2}\right]}$ and ${ }^{c} R_{\mathrm{wp}}{ }^{\prime}=\sqrt{\sum\left[w\left(Y_{\mathrm{obs}}-Y_{\text {calc }}\right)^{2}\right] / \sum\left[w\left(Y_{\mathrm{obs}}-\mathrm{bkgr}\right)^{2}\right]}$, where $y_{\mathrm{obs}}$ is the observed intensity, $y_{\text {calc }}$ the calculated intensity, $w$ the weight, and bkgr the background. 

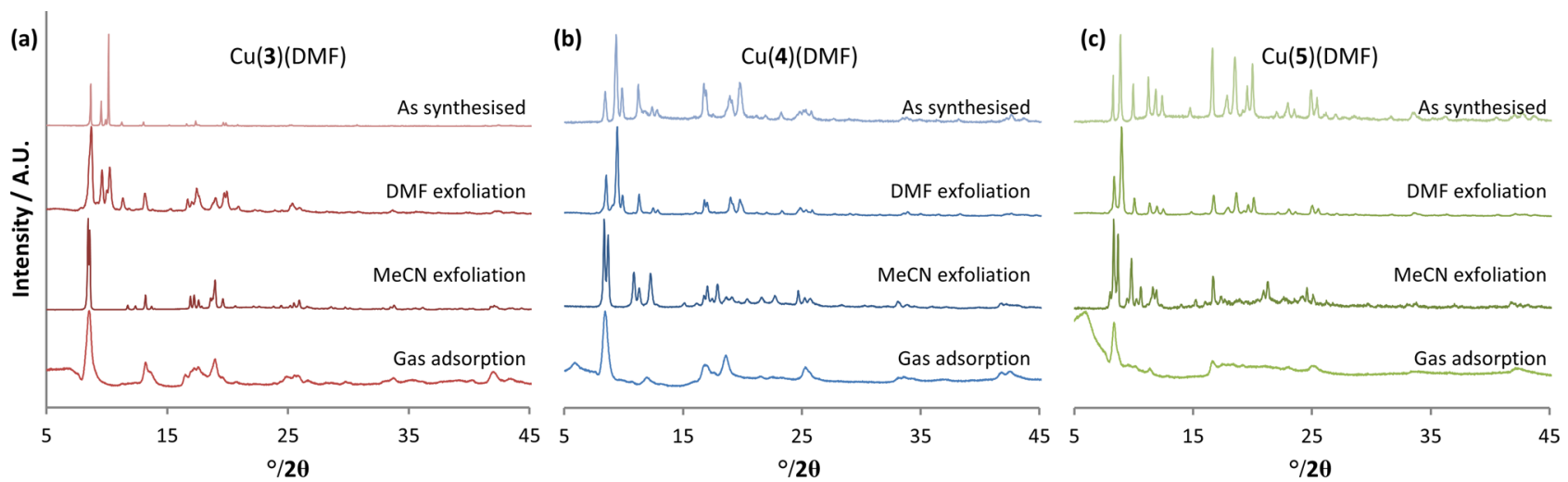

Figure 3. PXRD patterns $(\lambda=1.5406 \AA$ ) of (a) $\mathrm{Cu}(3)(\mathrm{DMF}),(\mathrm{b}) \mathrm{Cu}(4)(\mathrm{DMF})$, and (c) $\mathrm{Cu}(5)(\mathrm{DMF})$ MOFs after gas adsorption analyses and after exfoliation in DMF and MeCN, compared with as-synthesized MOFs.

dimer of neighboring layers to form a porous nonlayered $3 \mathrm{D}$ MOF, $\mathrm{Cu}(\mathrm{BDC}){ }^{61,62}$

Figure 3 shows PXRD patterns of $\mathrm{Cu}(\mathbf{3}-\mathbf{5})(\mathrm{DMF})$ after gas adsorption analyses and after sonication in DMF or $\mathrm{MeCN}$, compared with the as-synthesized MOFs. A distinct new PXRD pattern was observed for each of the MOFs following gas adsorption measurements or exfoliation in MeCN. Gas adsorption resulted in peak broadening and poorly defined patterns; however, peak positions broadly match those observed from exfoliating in $\mathrm{MeCN}$, indicating a similar phase has been formed in both cases. Sonication in $\mathrm{MeCN}$ gave sharper diffraction patterns. These samples were then digested using $\mathrm{DCl} / \mathrm{D}_{2} \mathrm{O}$ in $d_{6}$-DMSO for ${ }^{1} \mathrm{H}$ NMR spectroscopy. No DMF or MeCN was observed in any of the digested $\mathrm{Cu}(3-5)$ samples (Figures S23-S25), indicating that exfoliation in $\mathrm{MeCN}$ results in complete removal of DMF from compounds $\mathrm{Cu}(3-5)(\mathrm{DMF})$, and there is no coordination by $\mathrm{MeCN}$.

Pawley fitting of the PXRD patterns after exfoliation in $\mathrm{MeCN}$ indicated crystal phases distinct from the solvated MOFs, which were assigned as the desolvated phases $\mathrm{Cu}(3)$, $\mathrm{Cu}(4)$, and $\mathrm{Cu}(5)$ (Table 1 ). There are slight increases in unit cell volume compared to the solvated structures. Without a full structure solution, it is difficult to explain this. Locating the $\mathrm{Cu}$ atoms (Table S5) again allowed calculation of the interlayer distances in the same manner as for $\mathrm{Cu}(3-5)$ (DMF). These increased with the trend $8.68<9.37<10.03 \AA$ from $\mathrm{Cu}(3)$ to $\mathrm{Cu}(5)$, with the only notable increase upon desolvation being for $\mathrm{Cu}(3)(\mathrm{DMF})$ to $\mathrm{Cu}(3)(8.37-8.68 \AA)$. It is worth noting that these structures do not undergo the equivalent rearrangement upon desolvation of $\mathrm{Cu}(\mathrm{BDC})(\mathrm{DMF})$, instead maintaining their layered structure. We suggest this difference is due to the increased interlayer distance of $\mathrm{Cu}(n)(\mathrm{DMF})$ compared to $\mathrm{Cu}(\mathrm{BDC})(\mathrm{DMF})(5.2 \AA)$; sterics of the alkoxy arms may prevent the slipping of the layers and the close proximity needed to establish $3 \mathrm{D}$ coordination.

The diffraction patterns for all three frameworks following sonication in DMF were found to match those of the assynthesized material, indicating no substantial structural changes had occurred. Some broadening of the PXRD peaks was observed, most prominently in the case of $\mathrm{Cu}(3)(\mathrm{DMF})$, consistent with decreases in crystallite size during sonication.

2.3. Gas Adsorption. Figure 4 shows the $\mathrm{N}_{2}$ adsorption isotherms $(77 \mathrm{~K})$ for $\mathrm{Cu}(3-5)$. The BET surface areas were determined as $8.6,9.0$, and $5.4 \mathrm{~m}^{2} \mathrm{~g}^{-1}$, respectively. The type III adsorption isotherms, ${ }^{63}$ observed with negligible $\mathrm{N}_{2}$ uptake

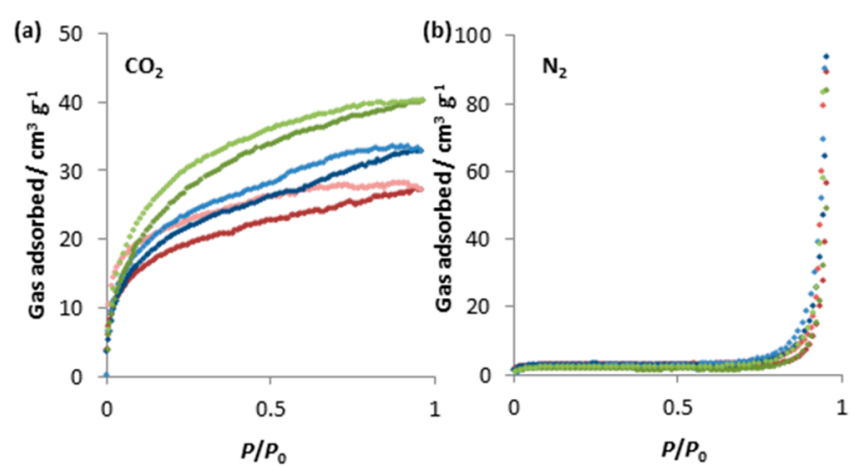

Figure 4. (a) $\mathrm{CO}_{2}$ and (b) $\mathrm{N}_{2}$ isotherms of $\mathrm{Cu}(3-5)$, recorded at 195 and $77 \mathrm{~K}$, respectively. Gas adsorption is represented by darker shades, and desorption by lighter shades. Isotherms for $\mathrm{Cu}(3), \mathrm{Cu}(4)$, and $\mathrm{Cu}(5)$ are red, blue, and green, respectively.

below $0.7 \mathrm{P} / \mathrm{P}_{0}$, are consistent with related alkoxy functionalized MOFs, where the pore space is not accessible for nonpolar gases. ${ }^{64} \mathrm{CO}_{2}$ adsorption $(195 \mathrm{~K})$ follows a type $\mathrm{Ib}$ isotherm, with a moderate type $\mathrm{H} 1$ hysteresis loop. $\mathrm{CO}_{2}$ uptake increases from 27.2 , to 32.9 , to $40.2 \mathrm{~cm}^{3} \mathrm{~g}^{-1}$, from $\mathrm{Cu}(3)$ to $\mathrm{Cu}(5)$. This relatively large uptake, compared to $\mathrm{N}_{2}$, could be due to increased penetration of the framework layers by $\mathrm{CO}_{2}$, which has a higher binding affinity for the $\mathrm{Cu}$ sites. The unit cell volume increases by $11 \%$ (1072 to $1197 \AA^{3}$, Table 1) from $\mathrm{Cu}(3)$ to $\mathrm{Cu}(5)$, which could account for the increasing uptake of $\mathrm{CO}_{2}$, also bearing in mind that the DMF has been removed, leaving coordinatively unsaturated $\mathrm{Cu}$ sites. If the unit cell volume remained constant across the series, it could be anticipated that the $\mathrm{CO}_{2}$ uptake would decrease with an increase in alkyl chain length, because of the increased packing density of the chains between the $2 \mathrm{D}$ framework layers, but this is presumably compensated by the observed unit cell expansion.

2.4. Ultrasonic Exfoliation To Form MONs. In order to exfoliate the MOFs, $5 \mathrm{mg}$ of $\mathrm{Cu}(3-5)(\mathrm{DMF})$ was suspended in $6 \mathrm{~mL}$ of DMF or $\mathrm{MeCN}$ and sonicated for $12 \mathrm{~h}$ in a water bath. Samples were rotated in the bath to ensure even exposure, and the bath was fitted with a water coil to maintain temperature, which equilibrated at $21{ }^{\circ} \mathrm{C} .{ }^{56}$ The samples were then centrifuged for either $1 \mathrm{~h}$ at $1500 \mathrm{rpm}$ or $4.5 \mathrm{~h}$ at 4500 rpm to remove the larger unexfoliated MOF crystallites. A calibration curve, obtained by serial dilution of a suspension containing a known mass of $\mathrm{Cu}(3-5)(\mathrm{DMF})$, was used to 
estimate the concentration of the nanosheets in suspension (Table 2 and Figures S26-S35).

Table 2. Concentration $\left(\mathrm{mg} \mathrm{mL}^{-1}\right)$ of MONs Remaining in Suspension Following Different Centrifugation Protocols

$\begin{array}{lllccc}\text { solvent } & \text { rate }^{a} & \begin{array}{c}\text { time } \\ (\mathrm{h})\end{array} & \begin{array}{c}\mathrm{Cu}(3) \\ (\mathrm{DMF})\end{array} & \begin{array}{c}\mathrm{Cu}(4) \\ (\mathrm{DMF})\end{array} & \begin{array}{c}\mathrm{Cu}(5) \\ (\mathrm{DMF})\end{array} \\ \text { DMF } & 1500 & 1 & 0.23 & 0.22 & 0.13 \\ & 4500 & 4.5 & 0.13 & 0.07 & 0.05 \\ \text { MeCN } & 1500 & 1 & 0.40 & 0.24 & 0.11 \\ & 4500 & 4.5 & 0.11 & 0.06 & 0.04\end{array}$

${ }^{a}$ Rate is in revolutions per minute (rpm).

As expected, the concentration of MONs in suspension decreased in all cases as the centrifugation rate increased from 1500 to $4500 \mathrm{rpm}$ (Table 2). No visible sedimentation was observed in any of the samples after a week. Interestingly, shorter alkyl chains resulted in higher concentrations of material in suspension after exfoliation in both DMF and $\mathrm{MeCN}$, from both centrifugation protocols. The concentration of material in suspension for $\mathrm{Cu}(3-5)(\mathrm{DMF})$ was higher following exfoliation in $\mathrm{DMF}$ than in $\mathrm{MeCN}$ following the faster (and longer) centrifugation protocol. From the slower (and shorter) centrifugation protocol, $\mathrm{Cu}(3-4)(\mathrm{DMF})$ had a higher concentration in $\mathrm{MeCN}$, but $\mathrm{Cu}(5)(\mathrm{DMF})$ had a higher concentration in DMF. These results demonstrate the importance of solvent-surface interactions in optimizing exfoliation and the effect that even small changes in the surface functionalities can have.

To assess the effect that chain length has on MON particle sizes following ultrasonic exfoliation in $\mathrm{MeCN}$, suspensions following centrifugation $(1500 \mathrm{rpm}, 1 \mathrm{~h}$ ) were deposited onto freshly cleaved mica and analyzed by AFM. A statistical analysis of the nanosheet dimensions was undertaken from resulting AFM images (Figures 5 and S36-S38). As the alkyl chain length increases from $\mathrm{Cu}(3)$ to $\mathrm{Cu}(5)$, the average thickness of the observed nanosheets decreased from $35 \mathrm{~nm}$,

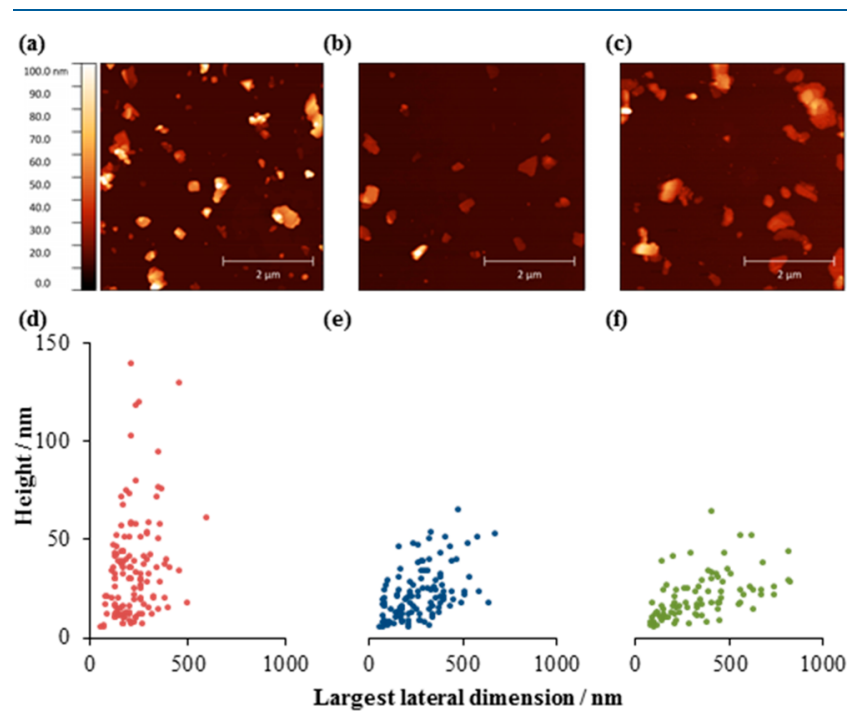

Figure 5. Topographic AFM images of nanosheets of $\mathrm{Cu}(3), \mathrm{Cu}(4)$, and $\mathrm{Cu}(5)(\mathrm{a}-\mathrm{c})$ observed after ultrasonic exfoliation of $\mathrm{Cu}(3-$ 5)(DMF) in MeCN, centrifugation (1500 rpm for $1 \mathrm{~h})$, and deposition onto mica. Associated scatter plots of MON dimensions $(d-f)$. through $22 \mathrm{~nm}$, to $20 \mathrm{~nm}$. Objects with heights of only $5 \mathrm{~nm}$ were observed in all three samples, corresponding to just five layers of framework. There is also an increase in lateral dimensions, from 222 to $348 \mathrm{~nm}$ across the series. These averages sit within a broad particle size distribution, with particles ranging between 50 and $900 \mathrm{~nm}$. However, the observed differences in lateral dimensions between $\mathrm{Cu}(3)-$ $\mathrm{Cu}(4)$ and $\mathrm{Cu}(4)-\mathrm{Cu}(5)$ are statistically significant (unpaired $t$ test at $99 \%$ confidence level), and differences in both lateral dimensions and height are significant between $\mathrm{Cu}(3)$ and $\mathrm{Cu}(5)$ (unpaired $t$ test, 99\% confidence level). Additionally, the general trends are corroborated through dynamic light scattering (DLS) measurements (Figure S42 and Table S6), which confirmed the mean hydrodynamic diameter increased $185<213<247 \mathrm{~nm}$ (Table 3). As noted elsewhere, DLS underestimates nanosheet lateral dimensions with respect to $\mathrm{AFM}^{65,66}$ in part because of the Stokes-Einstein equation assumption of spherical particles. ${ }^{67}$

Table 3. Summary of Statistical Size Data from $\mathrm{Cu}(3-5)$ MONs Observed after Exfoliation of MOFs Cu(3-5)(DMF) in $\mathrm{MeCN}^{a}$

\begin{tabular}{llll} 
& \multicolumn{1}{c}{$\mathrm{Cu}(3)$} & \multicolumn{1}{c}{$\mathrm{Cu}(4)$} & $\mathrm{Cu}(\mathbf{5})^{56}$ \\
$n$ & 129 & 114 & 94 \\
$\bar{x} \mathrm{LD} \pm \mathrm{SD}$ & $222 \pm 95$ & $275 \pm 148$ & $348 \pm 202$ \\
$\bar{x} H \pm \mathrm{SD}$ & $35 \pm 26$ & $22 \pm 13$ & $20 \pm 12$ \\
$\bar{x}{\text { aspect ratio } \pm \mathrm{SD}^{b}}^{c}$ & $10 \pm 7$ & $15 \pm 9$ & $19 \pm 10$ \\
diameter $^{c}$ & 185 & 213 & 247
\end{tabular}

${ }^{a} \mathrm{LD}=$ largest lateral dimension $(\mathrm{nm}) . H=$ height $(\mathrm{nm})$ and $\mathrm{SD}=$ standard deviation (nm). ${ }^{b}$ Mean aspect ratio determined for individual particles. ${ }^{c}$ Hydrodynamic diameter $(\mathrm{nm})$ according to number-averaged DLS data.

Overall, it is remarkable that increasing the alkyl chain length by just two methylene units almost doubles the aspect ratio of the nanosheets formed, from 10 to 19 . The opposite trend might be expected as each extra methylene unit will contribute additional van der Waals interactions. However, the longer alkyl chains also increase the interlayer distance, reducing other interlayer interactions and potentially making the layers easier to shear apart during sonication. Solvent is also expected to play a key role in offsetting the energy penalty for creating new interfaces during exfoliation. ${ }^{68,69}$ Contact angle measurements revealed complete surface wetting $\left(0^{\circ}\right)$ upon addition of either DMF or MeCN to thin films of $\mathrm{Cu}(3-$ 5) (DMF) MONs on mica compared to angles of $11^{\circ}$ and $14^{\circ}$, respectively, for uncoated mica surfaces. The decrease in concentration of material in suspension with increasing alkyl chain length indicates less favorable solvent-MON interactions. This could also result in more of the larger particles sedimenting out of suspension during centrifugation, resulting in a lower average particle size distribution for the MONs with longer alkyl chains. However, given the larger lateral dimensions of the nanosheets of $\mathrm{Cu}(5)$ compared to $\mathrm{Cu}(3)$, we suggest that weaker interlayer interactions are the major driver for the thinner nanosheets observed in this case.

In contrast to exfoliation in $\mathrm{MeCN}, \mathrm{AFM}$ analyses of the samples resulting from exfoliation in DMF showed only a small number of MONs with heights $<50 \mathrm{~nm}$ across all samples. $\mathrm{Cu}(3)(\mathrm{DMF})$ heights ranged from 50 to $200 \mathrm{~nm}, \mathrm{Cu}(4)$ (DMF) 40-150 nm and $\mathrm{Cu}(5)(\mathrm{DMF}) 40-350 \mathrm{~nm}$ (Figures S39-41) with a broad lateral size distribution comparable to 
those observed in $\mathrm{MeCN}$. A key difference between exfoliation in DMF compared to $\mathrm{MeCN}$ is that DMF remains coordinated to the axial position of the $\mathrm{Cu}-\mathrm{PW}$ throughout the exfoliation process when carried out in DMF, indicated by no change to the diffraction pattern post sonication in DMF (Figure 3). Considering $\mathrm{Cu}(5)(\mathrm{DMF})$, the alkyl chains and DMF from adjacent layers interdigitate, contributing to the interlayer interactions (see Figure 2). If DMF is removed, the interactions between the remaining alkyl chains are likely to be weaker, potentially accounting for the thinner MONs observed following exfoliation in $\mathrm{MeCN}$.

\section{CONCLUSIONS}

We have developed a series of layered MOFs incorporating ligands with alkyl side-chains of different length which are situated between the layers, in order to understand how this affects the nanosheets formed through liquid ultrasonic exfoliation of these MOFs. Ligands 1-5, which are 2,5bis(alkoxy)benzene-1,4-dicarboxylates with alkoxy chains ranging from methoxy to pentoxy, were used to generate a series of $\mathrm{Cu}$ PW-based layered MOFs. Pawley and Rietveld refinements of synchrotron PXRD data revealed that three of the compounds, $\mathrm{Cu}(3-5)(\mathrm{DMF})$, formed an isoreticular series of layered PW MOFs with the square-grid topology. The fully desolvated structures $\mathrm{Cu}(3-5)$ were also characterized by Pawley refinement, and both series of compounds showed an increase in unit cell volume with increasing alkyl chain length. $\mathrm{CO}_{2}$ uptake in the relatively dense layered frameworks increases by nearly $50 \%$ from 27.2 to $40.2 \mathrm{~cm}^{3} \mathrm{~g}^{-1}$ with an increase in chain length across the series $\mathrm{Cu}(3-5)$, whereas negligible $\mathrm{N}_{2}$ uptake was observed in all cases.

Liquid exfoliation in an ultrasonic bath produced suspensions of MONs in DMF and MeCN with shorter alkyl chains found to result in higher concentrations of material in suspension for both solvents. Although higher concentrations of material were typically observed in DMF, this was found to correspond to thick sheets $>50 \mathrm{~nm}$ in height. AFM revealed the formation of nanosheets in $\mathrm{MeCN}$ with thicknesses as low as $5 \mathrm{~nm}$, corresponding to just five layers of the framework. The difference in behavior between the two solvents was attributed to removal of the apical DMF from the $\mathrm{Cu}$ PWs in $\mathrm{MeCN}$, weakening interlayer interactions. We observed a decrease in the mean height of the MONs in MeCN from 35 $\mathrm{nm}>22 \mathrm{~nm}>20 \mathrm{~nm}$ for $\mathrm{Cu}(3)-\mathrm{Cu}(4)-\mathrm{Cu}(5)$, respectively. This trend of thinner nanosheets with increasing chain length was attributed to reducing the interlayer interactions and increasing the interlayer distance.

Together, these results demonstrate that an isoreticular series of MONs enables systematic studies to elucidate the rules governing the exfoliation of layered materials to form nanosheets. These insights will help in the design of new MOFs that are more readily exfoliated to form high concentrations of high-aspect-ratio nanosheets. The ability of MONs to be systematically tuned and optimized in this way provides them an advantage over other two-dimensional materials that are not modular in construction and will enable MONs to make an important contribution to sensing, catalysis, separation, electronics, and composite materials applications.

\section{EXPERIMENTAL SECTION}

Materials and reagents were obtained from multiple different commercial suppliers and used without further purification, specifically: dimethoxy-2,5-dihydroxybenzenedicarboxylate (Sigma-
Aldrich, 99+\%), methyl iodide (Alfa Aesar, 99\%, stabilized with copper), ethyl bromide (Sigma-Aldrich, 98\%), propyl bromide (Sigma-Aldrich, 99\%), butyl bromide (Acros, 99\%), pentyl bromide (Alfa Aesar, 99\%), copper nitrate trihydrate (SLS, 98\%), acetonitrile (Fisher, $\geq 99.9 \%$ ) and $n, n$-dimethylformamide (Fisher, $\geq 99 \%$ ).

4.1. Ligand Precursor Syntheses. Ligand precursors $\mathrm{H}_{2} 1$ to $\mathrm{H}_{2} 4$ were synthesized in close accordance with previously reported methodologies. ${ }^{54}$ Generally, dimethoxy-2,5-dihydroxybenzenedicarboxylate $(1 \mathrm{~g}, 4.42 \mathrm{mmol})$ and $\mathrm{K}_{2} \mathrm{CO}_{3}(1.83 \mathrm{~g}, 13.28 \mathrm{mmol})$ were placed in a Schlenk flask and suspended in $30 \mathrm{~mL}$ of $\mathrm{N}, \mathrm{N}$ dimethylformamide (DMF). The corresponding alkyl halide was added under stirring via syringe $(13.26 \mathrm{mmol}$ of methyl iodide, ethyl bromide, propyl bromide, butyl bromide, or pentyl bromide, respectively). The reaction mixture was stirred overnight at $85{ }^{\circ} \mathrm{C}$ and transferred into a round-bottom flask, and the DMF was removed under reduced pressure. A $\mathrm{NaOH}$ solution $\left(100 \mathrm{~mL} \mathrm{H} \mathrm{H}_{2} \mathrm{O}, 400 \mathrm{mg}\right.$ $\mathrm{NaOH}$ ) was added, and the product was refluxed overnight. After the mixture was allowed to cool to room temperature, aqueous $\mathrm{HCl}$ (10\%) was added to precipitate the products as off-white powders. Yields: $\mathrm{H}_{2} 1,91 \%$ (0.91 g, $\left.4.02 \mathrm{mmol}\right) ; \mathrm{H}_{2} 2,90 \%$ (0.91 g, $4.02 \mathrm{mmol}$ ); $\mathrm{H}_{2} 3$, 83\% (1.0 g, $3.55 \mathrm{mmol}$ ); $\mathrm{H}_{2} 4,86 \%$ ( $1.2 \mathrm{~g}, 3.88 \mathrm{mmol}$ ).

The method was adapted for $\mathrm{H}_{2} 5{ }^{47}$ A $2.089 \mathrm{~g}(9.24 \mathrm{mmol})$ sample of dimethoxy-2,5-dihydroxybenzenedicarboxylate was used, and other reagents were scaled accordingly. Instead of refluxing in $\mathrm{NaOH}(\mathrm{aq})$, the functionalized ester was refluxed in a 1:1 (v:v) mixture of THF and $\mathrm{KOH}(\mathrm{aq})(5 \%)$, before $\mathrm{HCl}$ workup in the same way to precipitate a white powder. Yield: $\mathrm{H}_{2} 5,87 \%(2.714 \mathrm{~g}, 8.02 \mathrm{mmol})$.

4.2. MOF Syntheses. Typically, $\mathrm{Cu}\left(\mathrm{NO}_{3}\right)_{2} \cdot 3 \mathrm{H}_{2} \mathrm{O}(100 \mathrm{mg}, 0.414$ $\mathrm{mmol}$ ) and $\mathrm{H}_{2}(1-5)$ ( $0.455 \mathrm{mmol}, 10 \%$ excess) were dissolved in 10 $\mathrm{mL}$ of DMF and sealed into $12 \mathrm{~mL}$ reaction vials with Teflon-lined lids. These were heated to $110^{\circ} \mathrm{C}$, held for $36 \mathrm{~h}$, and then cooled at $0.1{ }^{\circ} \mathrm{C} \min ^{-1}$ to $25{ }^{\circ} \mathrm{C}$. Green solids were isolated through centrifugation and washed with DMF $(3 \times 5 \mathrm{~mL})$ and diethyl ether $(2 \times 5 \mathrm{~mL})$. The resulting green microcrystalline powders were airdried prior to characterization. Yields: $\mathrm{Cu}(1)(\mathrm{DMF}), 82 \% ; \mathrm{Cu}(2)$ (DMF), 97\%; $\mathrm{Cu}(3)(\mathrm{DMF}), 93 \% ; \mathrm{Cu}(4)(\mathrm{DMF}), 82 \%$; $\mathrm{Cu}(5)-$ (DMF), 89\%. All yields are based on the anticipated structural formula $[\mathrm{Cu}(1-5)(\mathrm{DMF})]_{n}$ and calculated based on $\mathrm{Cu}$.

4.3. Ultrasonic Exfoliation. Five $\mathrm{mg}$ of the respective MOFs were suspended in $6 \mathrm{~mL}$ of solvent (DMF or MeCN). Mixtures were vortexed for $30 \mathrm{~s}$ before being placed in a Fisher brand Elmasonic P $30 \mathrm{H}$ ultrasonic bath $(2.75 \mathrm{~L}, 380 / 350 \mathrm{~W}$, UNSPSC 42281712) filled with water. Samples were held and rotated around the bath at $40 \mathrm{rpm}$ using an adapted Heidolph RZR 2020 overhead stirrer with a multisample holder. The ultrasonic bath was operated at $100 \%$ and 80 $\mathrm{kHz}$, and samples were sonicated for $12 \mathrm{~h}$. A cooling water coil was equipped to prevent bath heating upon prolonged use, with the bath temperature equilibrating at $21{ }^{\circ} \mathrm{C}$.

4.4. Characterization. TGA was performed using a PerkinElmer Pyris 1 TGA from 30 to $600{ }^{\circ} \mathrm{C}$ at $10^{\circ} \mathrm{C} \mathrm{min}^{-1}$, under a $20 \mathrm{~mL} \mathrm{~min}{ }^{-1}$ $\mathrm{N}_{2}$ flow. FTIR specta were recorded using a PerkinElmer Spectrum One spectrometer equipped with a diamond ATR accessory. Data were collected from 500 to $4000 \mathrm{~cm}^{-1}$ using a resolution of $1 \mathrm{~cm}^{-1}$ and 16 scans. Elemental analyses were performed using a Elementar vario MICRO cube. Samples for SEM analysis were loaded onto a carbon sticky tab on an aluminum sample stub and coated with approximately $20 \mathrm{~nm}$ of gold using an Edwards S150B sputter coater. SEM micrographs were collected using a TESCAN VEGA3 LMU SEM instrument, operating at $15 \mathrm{keV}$ and using the secondary electron detector. $\mathrm{N}_{2}$ and $\mathrm{CO}_{2}$ adsorption isotherms were measured using a Micromeritics 3 Flex volumetric gas adsorption instrument. Prior to dosing, samples were activated on the Micromeritics Smart Vac Prep Sample preparation station at $160^{\circ} \mathrm{C}$ and $10^{-3} \mathrm{mbar}$ for 10 h. Approximately $50 \mathrm{mg}$ of solid, dried sample was used in each case. $\mathrm{CO}_{2}$ and $\mathrm{N}_{2}$ gases used had purity grades of 99.5 and $99.999 \%$, respectively. $\mathrm{N}_{2}$ adsorption isotherms were recorded at $77 \mathrm{~K}$ using a liquid nitrogen bath for cooling of the sample cell, and $\mathrm{CO}_{2}$ adsorption isotherms were conducted at $195 \mathrm{~K}$ using a dry ice/ isopropanol slurry for cooling of the sample cell. The BrunauerEmmett-Teller equation was used to calculate the specific surface 
area from adsorption data obtained at $0.05 \leq P / P_{0} \leq 0.3 .{ }^{1} \mathrm{H}$ NMR spectroscopy was performed on a Bruker Avance IIIHD $400 \mathrm{MHz}$ spectrometer. ${ }^{1} \mathrm{H}$ chemical shifts are reported in parts per million on the $\delta$ scale and referenced to the residual proton resonance of the solvent. UV-vis spectra were recorded with a Varian Cary $50 \mathrm{UV}$ spectrophotometer using a resolution of $1 \mathrm{~nm}$ and scan speed of 600 $\mathrm{nm} \mathrm{min}^{-1}$, controlled with PerkinElmer Spectrum One software. Measurements were made using $10 \mathrm{~mm}$ path length quartz cuvettes. AFM images were obtained using a Bruker Multimode 5 AFM equipped with a Nokia $10 \times$ visualizing lens, operating in soft tappingmode using Bruker OTESPA-R3 cantilevers. Samples were prepared by dropping $10 \mu \mathrm{L}$ (sample dependent) of suspension onto a freshly cleaved mica substrate. Images were processed using standard techniques with Gwyddion software. ${ }^{70}$ DLS data were collected using a Malvern Zetasizer Nano Series particle size analyzer equipped with a $\mathrm{He}-\mathrm{Ne}$ laser at $633 \mathrm{~nm}$, operating in backscatter mode $\left(173^{\circ}\right)$. Contact angle measurements were made using a Ramé-Hart goniometer.

4.5. Powder X-ray Diffraction Data. PXRD data were recorded at the University of Sheffield on a Bruker D8 ADVANCE powder Xray diffractometer or using synchrotron radiation at beamline I11 at Diamond Light Source. ${ }^{71-73}$ Unit cell dimensions for samples $\mathrm{Cu}(3-$ 5)(DMF) were determined by indexing of synchrotron PXRD patterns in the range $3^{\circ} \leq 2 \theta \leq 40^{\circ}$ and fitting by Pawley refinement $^{74}$ using TOPAS software. ${ }^{75,76}$ A structural model for $\mathrm{Cu}(5)(\mathrm{DMF})$, adapted from a previously published single-crystal structure, ${ }^{47}$ was subsequently fitted to the PXRD pattern by Rietveld refinement $^{77}$ using TOPAS. Pawley and Rietveld refinement details are provided in the Supporting Information (Tables S3 and S4 and Figures S11-S20).

\section{ASSOCIATED CONTENT}

\section{(5) Supporting Information}

The Supporting Information is available free of charge on the ACS Publications website at DOI: 10.1021/acs.inorgchem.9b01128.

Material syntheses and characterization, PXRD refinement procedures, gas adsorption isotherms, UV data, AFM data, and statistical analyses (PDF)

\section{Accession Codes}

CCDC 1910582 contains the supplementary crystallographic data for this paper. These data can be obtained free of charge via www.ccdc.cam.ac.uk/data_request/cif, or by emailing data_request@ccdc.cam.ac.uk, or by contacting The Cambridge Crystallographic Data Centre, 12 Union Road, Cambridge CB2 1EZ, UK; fax: +44 1223336033.

\section{AUTHOR INFORMATION}

\section{Corresponding Author}

*E-mail: jona.foster@sheffield.ac.uk (J.A.F.).

\section{ORCID}

Andreas Schneemann: 0000-0001-6801-2735

Roland A. Fischer: 0000-0002-7532-5286

Lee Brammer: 0000-0001-6435-7197

Jonathan A. Foster: 0000-0002-0588-2474

Notes

The authors declare no competing financial interest.

\section{ACKNOWLEDGMENTS}

D.J.A. and J.A.F. thank the EPSRC (EP/K503149/1), the Ramsay Memorial Fellowship (JAF), and the University of Sheffield's Vice Chancellors Fellowship (JAF) for funding. T.M.R. and L.B. acknowledge the Leverhulme Foundation for funding. P.V. and R.A.F. acknowledge financial support from the German Research Foundation within research unit FOR2433. A.S. acknowledges the German Research Foundation for a Postdoctoral Fellowship. The authors thank Diamond Light Source for beam time; Drs. Stephen Thompson and Claire Murray at beamline I11 for assistance with data collection; and Michael Harris, Christopher Hill, and the University of Sheffield BioMedical Sciences EM unit for SEM analysis.

\section{REFERENCES}

(1) Ashworth, D. J.; Foster, J. A. Metal-Organic Framework Nanosheets (MONs): A New Dimension in Materials Chemistry. J. Mater. Chem. A 2018, 6 (34), 16292-16307.

(2) Zhao, M.; Huang, Y.; Peng, Y.; Huang, Z.; Ma, Q.; Zhang, H. Two-Dimensional Metal-Organic Framework Nanosheets: Synthesis and Applications. Chem. Soc. Rev. 2018, 47 (16), 6267-6295.

(3) Zhao, W.; Peng, J.; Wang, W.; Liu, S.; Zhao, Q.; Huang, W. Ultrathin Two-Dimensional Metal-Organic Framework Nanosheets for Functional Electronic Devices. Coord. Chem. Rev. 2018, 377, 4463.

(4) Xu, M.; Yang, S. S.; Gu, Z.-Y. Two-Dimensional Metal-Organic Framework Nanosheets: A Rapidly Growing Class of Versatile Nanomaterials for Gas Separation, MALDI-TOF Matrix and Biomimetic Applications. Chem. - Eur. J. 2018, 24, 15131-15142.

(5) Rodenas, T.; Luz, I.; Prieto, G.; Seoane, B.; Miro, H.; Corma, A.; Kapteijn, F.; Llabrés I Xamena, F. X.; Gascon, J. Metal-Organic Framework Nanosheets in Polymer Composite Materials for Gas Separation. Nat. Mater. 2015, 14 (1), 48-55.

(6) Ang, H.; Hong, L. Polycationic Polymer-Regulated Assembling of 2D MOF Nanosheets for High-Performance Nanofiltration. ACS Appl. Mater. Interfaces 2017, 9 (33), 28079-28088.

(7) Li, Z. Q.; Qiu, L. G.; Wang, W.; Xu, T.; Wu, Y.; Jiang, X. Fabrication of Nanosheets of a Fluorescent Metal-Organic Framework $[\mathrm{Zn}(\mathrm{BDC})(\mathrm{H} 2 \mathrm{O})] \mathrm{n}(\mathrm{BDC}=1,4-$ Benzenedicarboxylate $)$ : Ultrasonic Synthesis and Sensing of Ethylamine. Inorg. Chem. Commun. 2008, 11 (11), 1375-1377.

(8) Xu, H.; Gao, J.; Qian, X.; Wang, J.; He, H.; Cui, Y.; Yang, Y.; Wang, Z.; Qian, G. Metal-Organic Framework Nanosheets for FastResponse and Highly Sensitive Luminescent Sensing of Fe3+. J. Mater. Chem. A 2016, 4 (28), 10900-10905.

(9) He, L.; Duan, F.; Song, Y.; Guo, C.; Zhao, H.; Tian, J.-Y.; Zhang, Z.; Liu, C.-S.; Zhang, X.; Wang, P.; et al. 2D Zirconium-Based MetalOrganic Framework Nanosheets for Highly Sensitive Detection of Mucin 1: Consistency between Electrochemical and Surface Plasmon Resonance Methods. 2D Mater. 2017, 4 (2), 025098.

(10) Yang, Q.; Zhou, L.; Wu, Y. X.; Zhang, K.; Cao, Y.; Zhou, Y.; Wu, D.; Hu, F.; Gan, N. A Two Dimensional Metal-Organic Framework Nanosheets-Based Fluorescence Resonance Energy Transfer Aptasensor with Circular Strand-Replacement DNA Polymerization Target-Triggered Amplification Strategy for Homogenous Detection of Antibiotics. Anal. Chim. Acta 2018, 1020, 1-8.

(11) Chen, J.; Shu, Y.; Li, H.; Xu, Q.; Hu, X. Nickel Metal-Organic Framework 2D Nanosheets with Enhanced Peroxidase Nanozyme Activity for Colorimetric Detection of H2O2. Talanta 2018, 189 (March), 254-261.

(12) Hu, S.; Yan, J.; Huang, X.; Guo, L.; Lin, Z.; Luo, F.; Qiu, B.; Wong, K. Y.; Chen, G. A Sensing Platform for Hypoxanthine Detection Based on Amino-Functionalized Metal Organic Framework Nanosheet with Peroxidase Mimic and Fluorescence Properties. Sens. Actuators, B 2018, 267, 312-319.

(13) Zhan, G.; Zeng, H. C. Synthesis and Functionalization of Oriented Metal-Organic-Framework Nanosheets: Toward a Series of 2D Catalysts. Adv. Funct. Mater. 2016, 26 (19), 3268-3281.

(14) Cao, L.; Lin, Z.; Peng, F.; Wang, W.; Huang, R.; Wang, C.; Yan, J.; Liang, J.; Zhang, Z.; Zhang, T.; et al. Self-Supporting MetalOrganic Layers as Single-Site Solid Catalysts. Angew. Chem., Int. Ed. 2016, 55 (16), 4962-4966. 
(15) Huang, Y.; Zhao, M.; Han, S.; Lai, Z.; Yang, J.; Tan, C.; Ma, Q.; $\mathrm{Lu}, \mathrm{Q}$; Chen, J.; Zhang, X.; et al. Growth of Au Nanoparticles on 2D Metalloporphyrinic Metal-Organic Framework Nanosheets Used as Biomimetic Catalysts for Cascade Reactions. Adv. Mater. 2017, 29 (32), 1700102.

(16) Dong, R.; Zheng, Z.; Tranca, D. C.; Zhang, J.; Chandrasekhar, N.; Liu, S.; Zhuang, X.; Seifert, G.; Feng, X. Immobilizing Molecular Metal Dithiolene-Diamine Complexes on 2D Metal-Organic Frameworks for Electrocatalytic H2Production. Chem. - Eur. J. 2017, 23 (10), 2255-2260.

(17) Ling, P.; Qian, C.; Gao, F.; Lei, J. Enzyme-Immobilized MetalOrganic Framework Nanosheets as Tandem Catalysts for the Generation of Nitric Oxide. Chem. Commun. 2018, 54 (79), 11176-11179.

(18) Lan, G.; Li, Z.; Veroneau, S. S.; Zhu, Y.-Y.; Xu, Z.; Wang, C.; Lin, W. Photosensitizing Metal-Organic Layers for Efficient SunlightDriven Carbon Dioxide Reduction. J. Am. Chem. Soc. 2018, 140 (39), 12369-12373.

(19) He, T.; Ni, B.; Zhang, S.; Gong, Y.; Wang, H.; Gu, L.; Zhuang, J.; Hu, W.; Wang, X. Ultrathin 2D Zirconium Metal-Organic Framework Nanosheets: Preparation and Application in Photocatalysis. Small 2018, 14 (16), 1703929.

(20) Huang, J.; Li, Y.; Huang, R. K.; He, C. T.; Gong, L.; Hu, Q.; Wang, L.; Xu, Y. T.; Tian, X. Y.; Liu, S. Y.; et al. Electrochemical Exfoliation of Pillared-Layer Metal-Organic Framework to Boost the Oxygen Evolution Reaction. Angew. Chem., Int. Ed. 2018, 57 (17), $4632-4636$

(21) Saines, P. J.; Tan, J. C.; Yeung, H. H. M.; Barton, P. T.; Cheetham, A. K. Layered Inorganic-Organic Frameworks Based on the 2,2-Dimethylsuccinate Ligand: Structural Diversity and Its Effect on Nanosheet Exfoliation and Magnetic Properties. Dalt. Trans. 2012, 41 (28), 8585-8593.

(22) Sun, Z.; Hui, L.; Ran, W.; Lu, Y.; Jia, D. Facile Synthesis of Two-Dimensional (2D) Nanoporous NiO Nanosheets from MetalOrganic Frameworks with Superior Capacitive Properties. New J. Chem. 2016, 40 (2), 1100-1103.

(23) Benmansour, S.; Abhervé, A.; Gómez-Claramunt, P.; VallésGarcía, C.; Gómez-García, C. J. Nanosheets of Two-Dimensional Magnetic and Conducting $\mathrm{Fe}(\mathrm{II}) / \mathrm{Fe}(\mathrm{III})$ Mixed-Valence MetalOrganic Frameworks. ACS Appl. Mater. Interfaces 2017, 9 (31), 26210-26218.

(24) Hu, X.; Wang, Z.; Lin, B.; Zhang, C.; Cao, L.; Wang, T.; Zhang, J.; Wang, C.; Lin, W. Two-Dimensional Metal-Organic Layers as a Bright and Processable Phosphor for Fast White-Light Communication. Chem. - Eur. J. 2017, 23 (35), 8390-8394.

(25) Xing, W.; Ye, P.; Lu, J.; Wu, X.; Chen, Y.; Zhu, T.; Peng, A.; Huang, H. Tellurophene-Based Metal-Organic Framework Nanosheets for High-Performance Organic Solar Cells. J. Power Sources 2018, 401 (August), 13-19.

(26) Jayaramulu, K.; Masa, J.; Morales, D. M.; Tomanec, O.; Ranc, V.; Petr, M.; Wilde, P.; Chen, Y. T.; Zboril, R.; Schuhmann, W.; et al. Ultrathin 2D Cobalt Zeolite-Imidazole Framework Nanosheets for Electrocatalytic Oxygen Evolution. Adv. Sci. 2018, 5 (11), 1801029.

(27) Li, J.-R.; Kuppler, R. J.; Zhou, H.-C. Selective Gas Adsorption and Separation in Metal-Organic Frameworks. Chem. Soc. Rev. 2009, 38 (5), 1477.

(28) Huang, Y. B.; Liang, J.; Wang, X. S.; Cao, R. Multifunctional Metal-Organic Framework Catalysts: Synergistic Catalysis and Tandem Reactions. Chem. Soc. Rev. 2017, 46 (1), 126-157.

(29) Morris, R. E.; Brammer, L. Coordination Change, Lability and Hemilability in Metal-Organic Frameworks. Chem. Soc. Rev. 2017, 46 (17), 5444-5462.

(30) Evans, J. D.; Garai, B.; Reinsch, H.; Li, W.; Dissegna, S.; Bon, V.; Senkovska, I.; Fischer, R. A.; Kaskel, S.; Janiak, C.; et al. MetalOrganic Frameworks in Germany: From Synthesis to Function. Coord. Chem. Rev. 2019, 380, 378-418.

(31) Grigoropoulos, A.; McKay, A. I.; Katsoulidis, A. P.; Davies, R. P.; Haynes, A.; Brammer, L.; Xiao, J.; Weller, A. S.; Rosseinsky, M. J. Encapsulation of Crabtree's Catalyst in Sulfonated MIL-101(Cr):
Enhancement of Stability and Selectivity between Competing Reaction Pathways by the MOF Chemical Microenvironment. Angew. Chem., Int. Ed. 2018, 57 (17), 4532-4537.

(32) Xu, G.; Otsubo, K.; Yamada, T.; Sakaida, S.; Kitagawa, H. Superprotonic Conductivity in a Highly Oriented Crystalline MetalOrganic Framework Nanofil. J. Am. Chem. Soc. 2013, 135 (20), 7438-7441.

(33) Pustovarenko, A.; Goesten, M. G.; Sachdeva, S.; Shan, M.; Amghouz, Z.; Belmabkhout, Y.; Dikhtiarenko, A.; Rodenas, T.; Keskin, D.; Voets, I. K.; et al. Nanosheets of Nonlayered Aluminum Metal-Organic Frameworks through a Surfactant-Assisted Method. Adv. Mater. 2018, 30 (26), 1707234.

(34) Lan, G.; Li, Z.; Veroneau, S. S.; Zhu, Y.-Y.; Xu, Z.; Wang, C.; Lin, W. Photosensitizing Metal-Organic Layers for Efficient SunlightDriven Carbon Dioxide Reduction. J. Am. Chem. Soc. 2018, 140, 12369 .

(35) Wang, X.; Chi, C.; Zhang, K.; Qian, Y.; Gupta, K. M.; Kang, Z.; Jiang, J.; Zhao, D. Reversed Thermo-Switchable Molecular Sieving Membranes Composed of Two-Dimensional Metal-Organic Nanosheets for Gas Separation. Nat. Commun. 2017, 8, 14460.

(36) Peng, Y.; Li, Y.; Ban, Y.; Yang, W. Two-Dimensional MetalOrganic Framework Nanosheets for Membrane-Based Gas Separation. Angew. Chem., Int. Ed. 2017, 56 (33), 9757-9761.

(37) Peng, Y.; Li, Y.; Ban, Y.; Jin, H.; Jiao, W.; Liu, X.; Yang, W. Metal-Organic Framework Nanosheets as Building Blocks for Molecular Sieving Membranes. Science (Washington, DC, U. S.) 2014, 346 (6215), 1356.

(38) Ding, Y.; Chen, Y. P.; Zhang, X.; Chen, L.; Dong, Z.; Jiang, H. L.; Xu, H.; Zhou, H. C. Controlled Intercalation and Chemical Exfoliation of Layered Metal-Organic Frameworks Using a Chemically Labile Intercalating Agent. J. Am. Chem. Soc. 2017, 139 (27), 9136-9139.

(39) Song, W.-J. J. Intracellular DNA and MicroRNA Sensing Based on Metal-Organic Framework Nanosheets with Enzyme-Free Signal Amplification. Talanta 2017, 170 (February), 74-80.

(40) Chandrasekhar, P.; Mukhopadhyay, A.; Savitha, G.; Moorthy, J. N. Orthogonal Self-Assembly of a Trigonal Triptycene Triacid: Signaling of Exfoliation of Porous 2D Metal-Organic Layers by Fluorescence and Selective CO2capture by the Hydrogen-Bonded MOF. J. Mater. Chem. A 2017, 5 (11), 5402-5412.

(41) Ashworth, D. J.; Cooper, A.; Trueman, M.; Al-Saedi, R. W. M.; Smith, L. D.; Meijer, A. J.; Foster, J. A. Ultrasonic Exfoliation of Hydrophobic and Hydrophilic Metal-Organic Frameworks to Form Nanosheets. Chem. - Eur. J. 2018, 24 (68), 17986-17996.

(42) Li, P.-Z.; Maeda, Y.; Xu, Q. Top-down Fabrication of Crystalline Metal-Organic Framework Nanosheets. Chem. Commun. 2011, 47 (29), 8436-8438.

(43) Xu, G.; Yamada, T.; Otsubo, K.; Sakaida, S.; Kitagawa, H. Facile "Modular Assembly" for Fast Construction of a Highly Oriented Crystalline MOF Nanofilm. J. Am. Chem. Soc. 2012, 134 (40), 16524-16527.

(44) Tan, J. C.; Saines, P. J.; Bithell, E. G.; Cheetham, A. K. Hybrid Nanosheets of an Inorganic-Organic Framework Material: Facile Synthesis, Structure, and Elastic Properties. ACS Nano 2012, 6 (1), 615-621.

(45) Junggeburth, S. C.; Diehl, L.; Werner, S.; Duppel, V.; Sigle, W.; Lotsch, B. V. Ultrathin 2D Coordination Polymer Nanosheets by Surfactant-Mediated Synthesis. J. Am. Chem. Soc. 2013, 135, 61576164.

(46) Beldon, P. J.; Tominaka, S.; Singh, P.; Saha Dasgupta, T.; Bithell, E. G.; Cheetham, A. K. Layered Structures and Nanosheets of Pyrimidinethiolate Coordination Polymers. Chem. Commun. 2014, 50 (31), 3955-3957.

(47) Foster, J. A.; Henke, S.; Schneemann, A.; Fischer, R. A.; Cheetham, A. K. Liquid Exfoliation of Alkyl-Ether Functionalised Layered Metal-Organic Frameworks to Nanosheets. Chem. Commun. 2016, 52 (69), 10474-10477.

(48) Liu, H.-L.; Chang, Y.-J.; Fan, T.; Gu, Z.-Y. Two-Dimensional Metal-Organic Framework Nanosheets as a Matrix for Laser 
Desorption/Ionization of Small Molecules and Monitoring Enzymatic Reactions at High Salt Concentrations. Chem. Commun. 2016, 52 (88), 12984-12987.

(49) Cliffe, M. J.; Castillo-Martínez, E.; Wu, Y.; Lee, J.; Forse, A. C.; Firth, F. C. N.; Moghadam, P. Z.; Fairen-Jimenez, D.; Gaultois, M. W.; Hill, J. A.; et al. Metal-Organic Nanosheets Formed via DefectMediated Transformation of a Hafnium Metal-Organic Framework. J. Am. Chem. Soc. 2017, 139 (15), 5397-5404.

(50) Peng, Y.; Huang, Y.; Zhu, Y.; Chen, B.; Wang, L.; Lai, Z.; Zhang, Z.; Zhao, M.; Tan, C.; Yang, N.; et al. Ultrathin TwoDimensional Covalent Organic Framework Nanosheets: Preparation and Application in Highly Sensitive and Selective DNA Detection. J. Am. Chem. Soc. 2017, 139 (25), 8698-8704.

(51) Fan, Z.; Nomura, K.; Zhu, M.; Li, X.; Xue, J.; Majima, T.; Osakada, Y. Synthesis and Photocatalytic Activity of Ultrathin TwoDimensional Porphyrin Nanodisks via Covalent Organic Framework Exfoliation. Commun. Chem. 2019, 2 (1), 1-8.

(52) Kim, J.; Kwon, S.; Cho, D. H.; Kang, B.; Kwon, H.; Kim, Y.; Park, S. O.; Jung, G. Y.; Shin, E.; Kim, W. G.; et al. Direct Exfoliation and Dispersion of Two-Dimensional Materials in Pure Water via Temperature Control. Nat. Commun. 2015, 6, 1-9.

(53) Tiwari, P.; Kaur, N.; Sharma, V.; Mobin, S. M. High-Yield Graphene Produced from the Synergistic Effect of Inflated Temperature and Gelatin Offers High Stability and Cellular Compatibility. Phys. Chem. Chem. Phys. 2018, 20 (30), 20096-20107.

(54) Henke, S.; Schneemann, A.; Kapoor, S.; Winter, R.; Fischer, R. A. Zinc-1,4-Benzenedicarboxylate-Bipyridine Frameworks - Linker Functionalization Impacts Network Topology during Solvothermal Synthesis. J. Mater. Chem. 2012, 22 (3), 909-918.

(55) Henke, S.; Schneemann, A.; Wütscher, A.; Fischer, R. A. Directing the Breathing Behavior of Pillared-Layered Metal-Organic Frameworks via a Systematic Library of Functionalized Linkers Bearing Flexible Substituents. J. Am. Chem. Soc. 2012, 134 (22), 9464-9474.

(56) Ashworth, D. J.; Cooper, A.; Trueman, M.; Al-Saedi, R. W. M.; Smith, L. D.; Meijer, A. J. H. M.; Foster, J. A. Ultrasonic Exfoliation of Hydrophobic and Hydrophilic Metal-Organic Frameworks To Form Nanosheets. Chem. - Eur. J. 2018, 24 (68), 17986-17996.

(57) Coblentz Society, Inc. Evaluated Infrared Reference Spectra. In NIST Chemistry Web Book, NIST Standard Reference Database Number 69; Linstrom, P.J., Mallard, W.G., Eds.; National Institute of Standards and Technology: Gaithersburg MD; 20899. DOI: $10.18434 / \mathrm{T} 4 \mathrm{D} 303$.

(58) Li, H.; Eddaoudi, M.; Groy, T. L.; Yaghi, O. M. Establishing Microporosity in Open Metal-Organic Frameworks: Gas Sorption Isotherms for $\mathrm{Zn}(\mathrm{BDC})$ ( $\mathrm{BDC}=1,4-\mathrm{Benzenedicarboxylate).} \mathrm{J.} \mathrm{Am.}$ Chem. Soc. 1998, 120 (33), 8571-8572.

(59) Guo, Z.; Reddy, M. V.; Goh, B. M.; San, A. K. P.; Bao, Q.; Loh, K. P. Electrochemical Performance of Graphene and Copper Oxide Composites Synthesized from a Metal-Organic Framework (CuMOF). RSC Adv. 2013, 3 (41), 19051-19056.

(60) Eddaoudi, M.; Kim, J.; Rosi, N.; Vodak, D.; Wachter, J.; O'Keeffe, M.; Yaghi, O. M. Systematic Design of Pore Size and Functionality in Isoreticular MOFs and Their Application in Methane Storage. Science (Washington, DC, U. S.) 2002, 295 (5554), 469-472. (61) Carson, C. G.; Hardcastle, K.; Schwartz, J.; Liu, X.; Hoffmann, C.; Gerhardt, R. A.; Tannenbaum, R. Synthesis and Structure Characterization of Copper Terephthalate Metal-Organic Frameworks. Eur. J. Inorg. Chem. 2009, 2009 (16), 2338-2343.

(62) Carson, C. G.; Brunnello, G.; Lee, S. G.; Jang, S. S.; Gerhardt, R. A.; Tannenbaum, R. Structure Solution from Powder Diffraction of Copper 1,4- Benzenedicarboxylate. Eur. J. Inorg. Chem. 2014, 2014, 2140-2145.

(63) Thommes, M.; Kaneko, K.; Neimark, A. V.; Olivier, J. P.; Rodriguez-Reinoso, F.; Rouquerol, J.; Sing, K. S. W. Physisorption of Gases, with Special Reference to the Evaluation of Surface Area and Pore Size Distribution (IUPAC Technical Report). Pure Appl. Chem. 2015, 87 (9-10), 1051-1069.
(64) Schneemann, A.; Takahashi, Y.; Rudolf, R.; Noro, S.; Fischer, R. A. Influence of Co-Adsorbates on CO 2 Induced Phase Transition in Functionalized Pillared-Layered Metal-Organic Frameworks. J. Mater. Chem. A 2016, 4 (33), 12963-12972.

(65) Liscio, A.; Kouroupis-Agalou, K.; Betriu, X. D.; Kovtun, A.; et al. Evolution of the Size and Shape of 2D Nanosheets during Ultrasonic Fragmentation Evolution of the Size and Shape of 2D Nanosheets during Ultrasonic Fragmentation. 2D Mater. 2017, 4, 025017.

(66) Mukhopadhyay, A.; Maka, V. K.; Savitha, G.; Moorthy, J. N. Photochromic 2D Metal-Organic Framework Nanosheets (MONs): Design, Synthesis, and Functional MON-Ormosil Composite. Chem. 2018, 4 (5), 1059-1079.

(67) Lotya, M.; Rakovich, A.; Donegan, J. F.; Coleman, J. N. Measuring the Lateral Size of Liquid-Exfoliated Nanosheets with Dynamic Light Scattering. Nanotechnology 2013, 24 (26), 265703.

(68) Shen, J.; He, Y.; Wu, J.; Gao, C.; Keyshar, K.; Zhang, X.; Yang, Y.; Ye, M.; Vajtai, R.; Lou, J.; et al. Liquid Phase Exfoliation of TwoDimensional Materials by Directly Probing and Matching Surface Tension Components. Nano Lett. 2015, 15 (8), 5449-5454.

(69) Hernandez, Y.; Nicolosi, V.; Lotya, M.; Blighe, F. M.; Sun, Z.; De, S.; McGovern, I. T.; Holland, B.; Byrne, M.; Gun'ko, Y. K.; et al. High-Yield Production of Graphene by Liquid-Phase Exfoliation of Graphite. Nat. Nanotechnol. 2008, 3 (9), 563-568.

(70) Nečas, D.; Klapetek, P. Gwyddion: An Open-Source Software for SPM Data Analysis. Cent. Eur. J. Phys. 2012, 10 (1), 181-188.

(71) Tartoni, N.; Thompson, S. P.; Tang, C. C.; Willis, B. L.; Derbyshire, G. E.; Wright, A. G.; Jaye, S. C.; Homer, J. M.; Pizzey, J. D.; Bell, A. M. T. High-Performance X-Ray Detectors for the New Powder Diffraction Beamline I11 at Diamond. J. Synchrotron Radiat. 2008, 15 (1), 43-49.

(72) Thompson, S. P.; Parker, J. E.; Potter, J.; Hill, T. P.; Birt, A.; Cobb, T. M.; Yuan, F.; Tang, C. C. Beamline I11 at Diamond: A New Instrument for High Resolution Powder Diffraction. Rev. Sci. Instrum. 2009, 80 (7), 075107.

(73) Thompson, S. P.; Parker, J. E.; Marchal, J.; Potter, J.; Birt, A.; Yuan, F.; Fearn, R. D.; Lennie, A. R.; Street, S. R.; Tang, C. C. Fast XRay Powder Diffraction on I11 at Diamond. J. Synchrotron Radiat. 2011, 18 (4), 637-648.

(74) Pawley, G. S. Unit-Cell Refinement from Powder Diffraction Scans. J. Appl. Crystallogr. 1981, 14 (6), 357-361.

(75) Coelho, A. A. TOPAS Academic, version 4.1; see http://www. topas-academic.net.

(76) Coelho, A. A.; Evans, J.; Evans, I.; Kern, A.; Parsons, S. The TOPAS Symbolic Computation System. Powder Diffr. 2011, 26 (S1), S22-S25.

(77) Rietveld, H. M. A Profile Refinement Method for Nuclear and Magnetic Structures. J. Appl. Crystallogr. 1969, 2 (2), 65-71. 